\title{
FUNDAMENTOS GEOGRÁFICOS PARA A CONSERVAÇÃO DA NATUREZA
}

Manoel Carlos de OLIVEIRA*

Maria Helena de A. MELLO*

\begin{abstract}
RESUMO
Este trabalho visa mostrar que a Geografia Física, como fundamento científico, traz subsídios ao manejo correto dos recursos naturais.
\end{abstract}

\section{ABSTRACT}

This work deals with Phisical Geography, as scientific basis to carry out the nature resources management.

\section{INTRODUÇÃO}

Os danos provocados no meio natural pelo uso inadequado dos recursos naturais decorrem do aumento da demanda desses recursos para fins econômicos. As respostas desse meio aos impactos tecnológicos aparecem sob a forma de desequilíbrio estrutural e funcional da paisagem.

Essa afirmação hoje em dia é considerada um lugar comum. Mesmo assim, seria importante insistir neste aspecto do conflito entre homem e meio, que assume, cada vez mais, pontos críticos sem solução. O desenvolvimento técnicocientífico preocupa-se crescentemente em atender às necessidades humanas, sem levar em consideração as limitações da natureza.

Os freqüentes debates em torno do assunto mostram as mais divergentes opiniões. Argumenta-se que o referido desenvolvimento tecnológico representaria um mal e não teria nada a ver com a melhoria da qualidade de vida. Por outro lado, dentro da visão desenvolvimentista, o fator econômico chega a ter uma tão grande importância que os danos ao meio ambiente, causados pela ação desse fator, estariam fora de qualquer discussão. Algumas pessoas nem chegaram a tomar conhecimento dos níveis que o problema ambiental atinge, colocando em risco o futuro dos seres vivos sobre a Terra.

Em face de tantas posições divergentes e debates muitas vezes infrutíferos, de caráter mais filosófico que científico, torna-se urgente a adoção de medidas equilibradas e conscientes para a resolução dos problemas desencadeados pelo binômio homem-meio. Para tanto, são necessárias análises profundas baseadas em dados concretos para que sejam tomadas as devidas precauções, estabelecendo maneiras racionais de utilização do meio natural, de forma a impedir sua total destruição. Neste caso, trata-se não só de preservar o meio natural, como também de impedir conseqüências negativas posteriores que já se afiguram bastante drásticas.

Tendo em mente as discussões formuladas acima, os autores foram buscar na Geografia Física fundamentos científicos capazes de subsidiar programas de estudo que visem propor o manejo dos recursos naturais de maneira correta.

\section{DISCUSSÃO METODOLÓGICA}

A Geografia Física permite visualizar

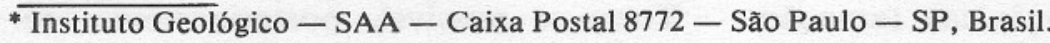




\begin{tabular}{|c|c|c|c|c|c|c|c|c|c|c|c|c|}
\hline \multirow{2}{*}{$\begin{array}{l}\text { Ramos da } \\
\text { Programas } \\
\text { específicos }\end{array}$} & \multicolumn{4}{|c|}{ G E O M O R F O LOGIA } & \multicolumn{4}{|c|}{ HIDROCLIMATOLOGIA } & \multicolumn{2}{|c|}{ OUTROS } & \multicolumn{2}{|c|}{ RAMOS } \\
\hline & $\mathbf{A}$ & B & $\mathrm{C}$ & D & E & F & G & $\mathbf{H}$ & I & $\mathrm{J}$ & K & $\mathrm{L}$ \\
\hline a & 5 & 1 & 4 & 4 & 2 & 2 & 1 & 4 & 2 & 4 & 4 & 4 \\
\hline b & 4 & 5 & 2 & 4 & 2 & 2 & 5 & 1 & 3 & 3 & 2 & 2 \\
\hline c & 3 & 3 & 4 & 1 & 3 & 3 & 5 & 2 & 4 & 4 & 4 & 4 \\
\hline d & 5 & 3 & 5 & 3 & 5 & 4 & 1 & 5 & 5 & 5 & 3 & 3 \\
\hline e & 1 & 1 & 1 & 1 & 5 & 5 & 4 & 2 & 1 & 5 & 4 & 4 \\
\hline
\end{tabular}

RAMOS DA GEOGRAFIA - TEMAS ESPECÍFICOS

GRAU DE RELAÇÃO

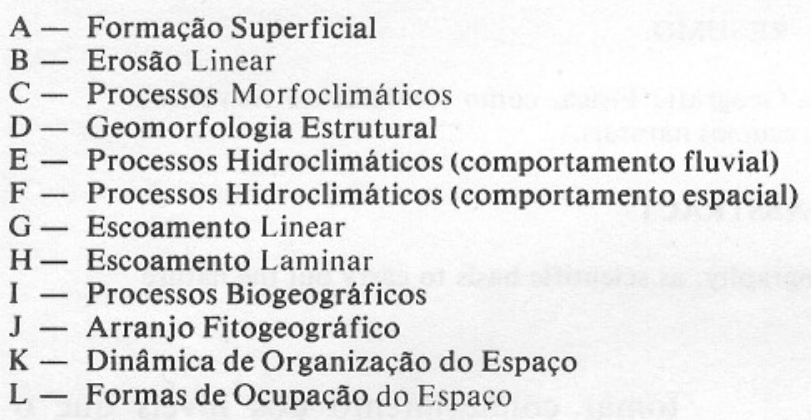

1 - MíNIMO

-

5-MÁXIMO

\section{PROGRAMAS ESPECÍFICOS}

a - Aceleração da erosão em áreas sedimentares

b - Deslizamento de encosta em áreas cristalinas

c - Assoreamento ao longo dos rios

$\mathrm{d}$ - Poluição de águas fluviais

e - Poluição de águas subterrâneas e/ou dimensionamento de aqüiferos para uso.

o conjunto de fatos integrantes da paisagem e possibilita a-realização de análises cuidadosas para avaliar os diferentes graus de interferência e de inter-relações das variáveis que caracterizam um determinado quadro natural. Os estudos dessa natureza, quando bem estruturados e colocados sobre bases reais, facilitam uma avaliação precisa das prováveis tendências evolutivas do meio natural, permitindo adotar medidas adequadas à sua preservação.

A linha metodológica indicada neste trabalho é baseada no que se conceitua como "análise da dinâmica de geossistemas naturais"'. Em Geografia, os geossistemas naturais ou espontâneos são entendidos como sistemas abertos, dinâmicos, hierarquicamente organizados, ou não. Apresentam uma relação de estado (realidade do espaço geográfico num dado momento) que é descrita pelo comportamento e conexão das variáveis físicas (ou do próprio meio natural) e/ou das variáveis antropogênicas (atuação do homem sobre o espaço). O estado dos geossistemas naturais é descrito pelo comportamento das variáveis do meio físico refletindo o comportamento das variáveis do meio humano. Guardadas as devidas precauções, permitem relacionar quantitativamente essas variáveis, facilitando a adoção de parâmetros que expressem de forma precisa certas relações procuradas. Permitem ainda avaliar e propor mais objetivamente diretrizes a serem tomadas em relação ao meio ambiente.

As técnicas adotadas para atender essa linha metodológica dizem respeito a sistemas cartográficos de classificação e de controle de informação. Essas técnicas permitem obter a visão de conjunto necessária para fins de diagnose de situação. O dimensionamento da situação a ser estudada deve ser realizado através de métodos estatísticos paramétricos e não paramétricos, de acordo com as possibilidades reais de sua utilização. Torna-se possível, posteriormente, re- 
correr à técnica de construção de modelos geossistêmicos, adequados à análise dos problemas ocasionados no meio natural. Tais modelos, desde que construídos de maneira adequada, permitem dimensionar as variáveis específicas que interferem em determinado problema. Nesse sentido é necessário levar em conta as características do meio físico de uma região em estudo. Cada fato terá sua posição dentro do geossistema montado. A adequação das escalas temporoespaciais desses modelos deve ser feita em função das necessidades impostas pela própria dimensão do problema a ser avalizado.

A realização do estudo descrito acima torna possível o estabelecimento de estratégias para a abordagem e solução dos problemas tidos como prioritários.

No quadro situado à página anterior está representado um exemplo esquemático da definição de alguns programas de pesquisa para atender assuntos prioritários, dentro da filosofia que norteia o método de análise de geossistemas.

Supondo que seja elaborado um estudo para subsidiar um programa de conservação da natureza, é possível, através de uma análise de prioridades, determinar os temas específicos no campo da Geografia Física que refletirão a realidade apresentada por determinado espaço geográfico. No caso do espaço geográfico paulista foram levantados alguns problemas que demandam medidas urgentes para sua solução:

1 - Problemas de aceleração da erosão em áreas sedimentares;

2 - Aceleração do processo de deslizamento de encostas em áreas cristalinas;

3 - Problemas de intensificação do assoreamento ao longo dos rios;

4 - Poluição das águas fluviais;

5 - Poluição de águas subterrâneas e/ou necessidade de dimensionar o potencial de aqüíferos para uso.

\section{LINHA DE AÇÃO}

A compreensão da dinâmica dos diferentes geossistemas, que compõem o espaço geográfico do Estado de São Paulo, só será possível graças à implantação de uma sistemática de pesquisas para a resolução de problemas específi- cos, de rotina ou/e urgentes. Tal programação deve ser criada para atender as entidades públicas e privadas, fornecendo-lhes subsídios para uma atuação compatível com uma politíca de promoção do meio ambiente.

Os autores têm em mente a importância de reorganizar uma infra-estrutura funcional adequada para o desenvolvimento de pesquisas que possibilitem traçar diretrizes de atuação, a curto, médio e longo prazo. Tomam-se como base as necessidades impostas pela atual realidade do meio ambiente no Estado de São Paulo.

A proposição de um programa de estudo, como o discutido neste trabalho, decorre da variedade e gravidade dos problemas ambientais acarretados pelo impacto maciço da ocupação humana no meio natural. Essa ocupação assume proporções de tal ordem que condicionam prejuízos não só para a qualidade de vida, como colocam em risco a própria economia paulista.

Os métodos de pesquisa em Geografia Física, adequados às reais condições tecnológicas e ambientais, podem ser obtidos através da utilização de modelos de geossistema como instrumento de diagnose de problemas para fins de resultados aplicados. Em função da gravidade dos problemas fisiográficos desencadeados pela forma de ocupação do meio natural, é fundamental a determinação de áreas prioritárias no Estado de São Paulo para a montagem de um programa de pesquisa visando à preservação da natureza.

Outro aspecto importante hoje em dia refere-se ao estabelecimento de estratégias para desenvolver projetos em Geografia Física, visando à integração com outras áreas das Geociências e com outras ciências afins. A ciência geográfica, por sua natureza, promove uma maior facilidade de integração com outras ciências ambientais. Os produtos de pesquisa integrados em Geografia Física fornecem bons subsídios à tomada de decisões políticas quanto ao uso racional do espaço.

A preocupação com a educação ambiental deve ser levada em consideração quando se discute o aperfeiçoamento de técnicos ligados ao meio ambiente. A ca- 
pacidade de tomada de decisão requer um contínuo aprimoramento a nível de indivíduo. Portanto, todo programa de trabalho deve pressupor, além das atividades geradas pelo mesmo, o aprimoramento do corpo técnico que dele participa. Atualmente o volume de informação sobre meio ambiente é de tal ordem que obriga o pessoal técnico a uma constante reciclagem de conhecimentos.

\section{CONSIDERAÇÕES FINAIS}

As bases filosóficas de um programa de conservação da natureza vinculam-se à urgente necessidade de uma revisão da política de ocupação do espaço bem como do redimensionamento da política técnico-científica para satisfazer tal necessidade. Nesse sentido o cumprimento da demanda de pesquisas requer esquemas racionais, para que elas possam funcionar. Essas pesquisas devem atender às diretrizes, não só de uma política técnico-científica, como de uma conjuntura político-administrativa e sócioeconômica do Estado de São Paulo.

\section{REFERÊNCIAS BIBLIOGRÁFICAS}

BERTRAND, G. 1971 Paisagem e geografia física global: esboço metodológico. São Paulo, Universidade, Instituto de Geografia, 27p. (Caderno de Ciências da Terra, 13).

DEMEK, J. 1978 The landscape as a geosystem. Geoforum, Oxford, 9 (1): 29-34.

MONTEIRO, C.A. de Figueiredo. 1978 Derivações antropogênicas dos geossistemas terrestres no Brasil e alterações climáticas: perspectivas urbanas e agrárias do problema da elaboração de modelos de avaliação. In: SIMPÓSIO SOBRE A COMUNIDADE VEGETAL COMO UNIDADE BIOLÓGICA,
TURÍSTICA E ECONÔMICA, Anais, São Paulo, Secretaria da Cultura, Ciência e Tecnologia, Academia de Ciências do Estado de São Paulo. p. 43/75 (Publicação ACIESP, 15).

OLIVEIRA, M.C. 1982 Discussões sobre o conceito de meio ambiente. Revista do Instituto Geológico, São Paulo, 3(2): 53-69, jul/dez.

1983 Paisagem, meio ambiente e planejamento. Revista do Instituto Geológico, São Paulo, 4 (1/2): 67-78, jan/dez.

SOTCHAVA, V.B. 1977 O estudo de geossistema. São Paulo, Universidade, Instituto de Geografia. 52p. (Métodos em Questão, 16.) 